\title{
Midiatização da saúde: as perspectivas de uma vida saudável no ecossistema jornalístico
}

\section{Thalita Mascarelo da Silva}

Universidade Federal do Espírito Santo, Vitória, ES, Brasil

ORCID: http://orcid.org/0000-0002-0703-8226

\section{Victor Israel Gentilli}

Universidade Federal do Espírito Santo, Vitória, ES, Brasil

ORCID: http://orcid.org/0000-0001-9952-2949

\section{Resumo}

Este trabalho apresenta um breve panorama sobre a relação dos meios de comunicação com assuntos da saúde a partir do protagonismo das fontes de informação especializadas, suas particularidades e discussões. Portanto, o nosso objetivo é de compreender o papel da informação na construção de conceitos em saúde no atual contexto de midiatização social. Dessa forma, o percurso metodológico vislumbrou reunir vertentes de estudo sobre o tema midiatização da saúde e problematizar a lógica da prática da construção de perspectivas sobre vida saudável, a partir das fontes de informação no ecossistema jornalístico. Os resultados demonstraram que as novas mediações criam relações e interações complexas entre a utilização de conceitos nas novas mídias sociais pelos profissionais de saúde em suas dinâmicas com o público em geral.

\section{Palavras-chave}

Fontes de Informação; Promoção da Saúde; Jornalismo em Saúde; Comunicação e Saúde; Midiatização

\section{Introdução}

Como se manifesta a midiatização no jornalismo digital na perspectiva das fontes de informação? A discussão se baseia na ideia de ressignificação das relações sociais das fontes de informações especializadas em saúde no que diz respeito a informar nas redes sociais, multiplicando-se em um grande ecossistema jornalístico. Tal ecossistema cria novos espaços 
informacionais que disputam narrativamente perspectivas sobre assuntos pertinentes e de interesse público, como a ideia de uma vida saudável.

O ecossistema jornalístico será um conceito importante, portanto, para o entendimento da ascensão de um determinado agente no jornalismo: as autoridades sociais, as quais fazem parte de um público muito particular do jornalismo, pois participam do campo jornalístico como fontes de notícias que fornecem sua credibilidade, enquanto especialistas em determinada área, à notícia. Isso ao mesmo tempo em que, nos próprios canais de comunicação nas redes sociais, são fontes de informação, misturando-se aos mais diversos públicos atuando em um ecossistema jornalístico. Portanto, é necessário compreender a transformação desses atores científicos específicos no jornalismo.

A comunicação e a informação despontam como questões substanciais do século XXI, principalmente quando agregadas às inovações tecnológicas as quais constituem fenômenos sociais transformadores, amplamente discutidos na atualidade. Diante disso, vale destacar a importância de se perceber a tecnologia vinculada à comunicação de maneira histórico-social, agregando importância transformadora desde o aparecimento de linhas de telégrafo internacionais, as quais já propiciavam uma diferenciação no que diz respeito à sensação de tempo e espaço comprimidos, ainda no século XIX (AMPUJA, 2015).

É de relevância ímpar a concepção histórica sobre o peso da tecnologia para que se tenha uma melhor perspectiva atual de sua dimensão, uma vez que o artigo proposto busca compreender um fenômeno dito contemporâneo, o qual traz a tecnologia como ponto significativo, sendo, portanto, resultado de um contexto histórico construído e desenvolvido desde a invenção da imprensa, no século XV, a qual surgira como uma inovação tecnológica que possibilitou uma circulação de informação até então sem precedentes.

A construção de ferrovias pode ser entendida como um começo no avanço tecnológico comunicacional, pois abriu os caminhos para o processo da globalização na modernidade, a partir de novas conexões e temporalidades, fazendo que a relação entre transporte e comunicação seja importante para se compreender a relação espaço-tempo em um mundo de interligações globais auxiliadas com a ferrovia, e também, por meio do telégrafo, do telefone, do rádio, do cinema, da televisão, da internet (SILVERSTONE, 2002).

O que agora definimos como globalização e o que agora anunciamos como um admirável mundo novo liberado pelas maravilhas do eletrônico e do digital têm uma história. Uma história da máquina, uma história das instituições e indústrias que cresceram em torno da máquina e uma história 
das coisas, das pessoas, das notícias, das imagens, das ideias, dos valores que eram transmitidos pela máquina. E, pelo fato de a globalização ter uma história, devemos ter o cuidado de não a atribuir exclusivamente à condição pós-moderna. (SILVERSTONE, 2002, p. 198-199).

0 fenômeno denominado midiatização será um dos condutores centrais deste trabalho, porque posiciona as mídias - mais especificamente o jornalismo - no bojo da problemática questão de como está acontecendo a relação entre atores da saúde a partir das novas mediações, tendo como premissa a comunicação como aspecto constituidor da vida social (FRANCA, 2003). Tendo isso como ponto de partida, entende-se como primordial a compreensão do conceito de midiatização imbricado ao de mediação. 0 objetivo é analisar como as fontes de notícias fazem parte desse processo social vigente, uma vez que transformações no âmbito midiático provocam mudanças também em seus atores constitutivos.

Os meios de comunicação estão relacionados a processos de ação e interação, os quais mediam relações sociais, sendo, por isso, de caráter dialógico, através de sinalizações simbólicas (THOMPSON, 2018). Diante do exposto, o texto busca discutir os impasses que existem no contexto digital das fontes de informações especializadas em saúde no panorama brasileiro, além de fazer um esforço na compreensão da ideia de vida saudável construída, uma vez que a conscientização dos cidadãos através da informação dada por especialistas em saúde alcança maior credibilidade e amplitude nas redes.

\section{Perspectivas de uma vida saudável}

A procura por um estilo de vida saudável perpassa cada vez mais o imaginário social, fazendo que informações sobre saúde nessa perspectiva apareçam tanto como de interesse público quanto como de interesse do público. "[...] Mais que uma função social, o serviço ao interesse público é valor eminente e o princípio que o prescreve torna-se uma determinação moral. [...]" (GOMES, 2009, p. 70). É papel do jornalista publicar notícias a partir do interesse público entendido como direito à informação. A imprensa representa uma perspectiva informacional no debate público, assim como - atualmente - as redes sociais utilizadas por especialistas, pois possuem o capital simbólico da informação e também fazem parte desse processo a partir de outra perspectiva, mas que igualmente angariam a ideia do princípio do interesse público. 
Assuntos sobre saúde passaram a ser divulgados de modo mais abrangente a partir dos anos 1990 devido a uma série de fatores, como uma maior disponibilidade das fontes em saúde em relação aos jornalistas e a crescente profissionalização da área imbricada à comunicação como marketing e assessorias estabelecidas para os agentes da saúde (LOPES, et. al, 2011). Especificamente no Brasil, foi a partir do final dos anos 1980 que a saúde se tornou uma obrigação pública. Além de meras questões biológicas do corpo, a saúde se transformou em pauta coletiva e universal, culminando em registro oficial na Constituição de 1988 pela criação do Sistema Único de Saúde, conquista esta alcançada principalmente com a militância do Movimento da Reforma Sanitária (PAIM, 2009).

O tema saúde, portanto, vem crescendo no cenário jornalístico e surge, assim, como um valor-notícia determinante para a edição dos jornais, o que garante grande investimento dos periódicos no assunto, inclusive com caderno próprio em alguns deles, colunas fixas sobre o tema, grandes reportagens, além de especialistas da área contratados, como cita 0 Globo (2012) a partir da sentença: “O comentário da seção 'Por dentro do Globo', ao justificar a contratação de um médico: 'Saúde é sempre um tema campeão entre os assuntos mais desejados pelos leitores"' LERNER; CARDOSO; ARAÚJO (2013 apud LERNER; SACRAMENTO, 2014, p. 17).

Tal crescimento pode ser verificado mediante uma rápida observação dos principais produtos jornalísticos: nota-se a profusão de capas de revistas e jornais, programas de televisão e matérias de sites noticiosos com informações sobre os novos medicamentos lançados, a importância de fazer dieta, a eclosão de uma nova epidemia, o surgimento de um tipo diferente de dengue. (LERNER; SACRAMENTO, 2014, p. 16).

Seja no jornalismo, seja na rede social de um especialista em saúde, perspectivas sobre vida saudável são criadas, culminando na criação de um imaginário social a partir de uma disputa de narrativas em diferentes espaços comunicacionais. A circulação de informações de interesse público fornece à sociedade a possibilidade de representação social; no entanto, para que de fato aconteça, o cidadão precisa ser visto para além de um consumidor de notícias.

O jornalismo continua tendo, no cenário social, a importância de informar sobre o que é de interesse público. Para isso, precisa lutar pela sua autonomia de informar, negando-se à

${ }^{1}$ LERNER, K; CARDOSO, J. \&ARAÚJO, I. Pesquisa e ensino em comunicação e saúde no Brasil. In: BARBOSA, M; SACRAMENTO, I. \&MACHADO, M. B. (Orgs.). Panorama das Comunicações e Telecomunicações no Brasil, 2012-2013. Brasília: Ipea, 2013. Apud Lerner; Sacramento (2014). 
submissão completa às questões econômicas e políticas. Assim como, quem se dispuser a informar também tem de entender a responsabilidade moral e social desse processo.

[...] 0 pacto da mediação cobra do jornalismo obrigações proporcionais à sua importância. Verdade, honestidade, correção, lealdade, respeito, equilíbrio, justiça, imparcialidade são todos valores e princípios que devem orientar uma ética do jornalismo mesmo lá onde o serviço ao interesse público não fizer sentido nem tiver cabimento. (GOMES, 2009, p. 87).

Inúmeros sentidos são construídos a partir da interpretação do real construído historicamente. É o que acontece com a criação de conceitos como o de vida saudável, sendo importante no que diz respeito à construção de um conhecimento, para que se delimite e haja legitimação, a partir de determinada perspectiva, a busca por uma proximidade com a objetividade (HENRIQUES, 2019). Quando um dermatologista, a partir das suas redes sociais, informa sobre sua especificidade, uma perspectiva sobre vida saudável é efetivada, assim como uma reportagem sobre alimentação em jornal traz outra perspectiva; isto é, vida saudável consiste em um conceito com diversos sentidos e, por isso, a completude da expressão dificilmente será explorada em uma única postagem. Desse modo, para que o texto seja mais bem esclarecido, ele precisa explicitar de qual perspectiva origina o pensamento construído, seja na notícia, seja numa postagem informativa em uma rede social.

Narrativas sobre a ideia do ser saudável somente podem ser alcançadas se compreendidas de modo amplo e coletivo, a partir de outros conceitos, como qualidade de vida e bem-estar, o que torna imprescindível a ideia de promoção da saúde (SANTOS et. al, 2019).

A promoção da saúde foi nominada, pela primeira vez, pelo sanitarista Henry Sigerist, no início do século XX. Ele elaborou as quatro funções da Medicina: promoção da saúde, prevenção das doenças, tratamentos dos doentes e reabilitação. Segundo essa concepção, a promoção da saúde envolveria ações de educação em saúde e ações estruturais do Estado para melhorar as condições de vida da população (DEMARZO; AQUILANTE, 2008).

A crise econômica da década de 1970, em paralelo com a crescente força do neoliberalismo, o alto custo das tecnologias do setor médico e o modelo tradicional da medicina, foi o pano de fundo para que ocorresse, no Canadá, um marco significativo na construção do conceito de promoção da saúde: o Relatório Lalonde, de 1981 (COSTA; MISOCZKY; ABDALA, 2018). Marc Lalonde ocupava o cargo de Ministro da Saúde no Canadá, 
na década de 1970, e contribuiu na investigação dos indicadores relacionados à saúde dos canadenses (LALONDE, 1981). Lalonde constatou que as maiores causas de doenças no país relacionavam-se ao estilo de vida e ao ambiente, portanto, apesar de críticas terem sido feitas a esse relatório, essencialmente devido à ênfase na individualização e no estilo de vida dos sujeitos, Lalonde também atribuiu ao governo a responsabilidade das questões sobre o meio ambiente, no que tange à poluição do ar, ao abastecimento de água etc., o que significou um avanço no processo de conceitualização da promoção da saúde.

Após quatro anos do Relatório Lalonde, houve a primeira Conferência Internacional sobre Cuidados Primários em Saúde, no Cazaquistão, a qual resultou na Declaração de AlmaAta que expressava a necessidade da ação de todos os governos, do campo da saúde e dos campos do desenvolvimento, no sentido de promover a saúde. A Declaração de Alma-Ata (1978) enfatiza saúde como estado de completo bem-estar físico, mental e social, como um direito humano fundamental, e estabelece como meta social e política mundial ações para a realização da plena saúde para os povos, juntamente com setores sociais e econômicos, além de priorizar a Atenção Primária em Saúde (APS). Constatou-se que, para promover saúde, é preciso educação, redução da desigualdade social, participação economicamente ativa dos cidadãos, lazer etc. (DECLARAÇÃO DE ALMA-ATA, 1978).

Dessa maneira, evidenciou-se: falar em promoção da saúde significa entender saúde como um conceito que engloba um conjunto de fatores que vão além do setor da saúde. Sendo assim, para promover saúde, é necessário, primeiramente, fazer uma discussão sobre saúde em seu sentido amplo. A promoção contempla a questão da saúde pública com uma visão abrangente que renega o entendimento de doença como fatalidade natural. Assim, para se compreender o conceito de promoção da saúde é necessário, primeiro, apreender o conceito de saúde para além da ausência de doenças (BUENO, 2007).

0 ano de 1986 concerniu em um ano simbólico para a luta da promoção da saúde, pois foi marcado pela primeira Conferência Internacional sobre o tema, que culminou na Carta de Ottawa. O documento definia, mundialmente, os cinco pilares para a construção da promoção da saúde: a implantação de políticas públicas saudáveis, a criação de ambientes saudáveis à saúde, a reorientação dos serviços de saúde, o reforço à ação comunitária, o desenvolvimento de habilidades pessoais, ou seja, a capacitação das pessoas, e a divulgação de informações (CARTA DE OTTAWA, 1986).

A datar dessa primeira Conferência Internacional de Promoção da Saúde, depreendese a evolução do conceito, a partir da Carta de Ottawa, que continua sendo o grande pilar em 
relação a essa discussão. Os pré-requisitos, portanto, para os cuidados básicos em saúde foram desenvolvidos através da constatação da necessidade de paz, habitação, educação, alimentação, renda ambiente, recursos sustentáveis, justiça social e equidade. A Carta de Ottawa, dessa forma, foi um marco primordial para a discussão sobre promoção da saúde como um conceito amplo que demanda um conjunto de valores: "solidariedade, equidade, democracia, cidadania, desenvolvimento, participação e ação conjunta" (COSTA; MISOCZKY; ABDALA, 2018, p. 998).

A última conferência em nível global sobre o tema aconteceu em 2018, ano em que foram completados 40 anos da Declaração de Alma-Ata. Nesse evento, realizado em Astana, foi apresentada a Declaração de Astana, que buscou elencar e discutir assuntos cujo tema central recai sobre a saúde, desde a APS aos temas mais específicos, como saúde mental. No entanto, abordou também de forma ampla, envolvendo debates sobre os determinantes da saúde. Houve participação governamental, da sociedade civil, do setor privado e da comunidade acadêmica (GADELHA; TEMPORÃO, 2018). A Declaração de Astana contribui para a continuidade da discussão sobre promoção da saúde, todavia, a Declaração de AlmaAta continua sendo um marco histórico na discussão, pois enfatizou ideários que permanecem essenciais para uma melhor discussão sobre saúde para todos, como justiça social e desenvolvimento econômico e social dos países em prol da redução das desigualdades.

É imprescindível ressaltar, a partir do cenário enunciado, a saúde no seu sentido amplo, não apenas como ausência de doenças, mas determinada por diversos fatores. Sendo assim, não se deve transportar o problema do corpo social para o corpo biológico, como se somente a ação individual das pessoas determinasse a sua saúde ou ausência dela. A maior significância da promoção da saúde está justamente na amplitude que se formou em seu conceito, da sua articulação com outras concepções, não somente a prevenção de doenças, uma vez que promover saúde engloba aspectos sociais, econômicos e políticos, envolvendo cidadania, democracia, equidade etc. (ROCHA; PADILHA, 2016).

O enfrentamento maior no que tange à promoção da saúde, no contexto neoliberal, consiste no combate ao radicalismo, sobre o qual se reduz a discussão do aspecto individualizador e culpabilizador que entende a escolha dos sujeitos como o bojo da questão. Hall (2016) explica a errônea predileção de se ater a um "reducionismo comportamental" sobre questões relacionais complexas que envolvem pensamento, discurso, prática e estrutura. 0 enfoque na culpabilização do indivíduo ignora processos sociais, desconsidera o 
aspecto crítico do tema e despolitiza o problema, desprezando, inclusive, a própria cultura na qual se está inserido (HALL, 2016).

No que diz respeito à promoção da saúde, o debate sobre vida saudável precisa alcançar uma profundidade maior, no esforço de discernir os motivos de determinadas escolhas, de determinados comportamentos e, para isso, faz-se crucial o entendimento da macroestrutura ao redor daquele indivíduo: o seu contexto socioeconômico, o seu local de trabalho, a sua cultural local. Dessa forma, a presença do Estado, do interesse no que é público aparece como pilar principal, uma vez que somente com infraestruturas efetivas que se promove saúde em seu sentido amplo (MORAES; CASTIEL, 2019). As falhas sanitárias existentes no ambiente em sociedade não podem ser tratadas pelo Estado como problemáticas da conduta dos indivíduos e, consequentemente, ignoradas como se somente decisões individuais fossem gerar maior qualidade de vida e bem-estar para a população.

O Estado, portanto, deve participar ativamente na prática da promoção da saúde para que resultados possam ser concretizados formulando políticas públicas, orientando a participação populacional a partir de informações e ações relacionadas à saúde, além de criar ambientes favoráveis e que facilitem melhores escolhas individuais à saúde (ROCHA; PADILHA, 2016). Promover saúde consiste em facilitar a escolha saudável dos indivíduos e dificultar as que não são saudáveis, principalmente a partir de políticas públicas, por exemplo, a proibição de fumar em ambientes fechados promove saúde, já a flexibilização de leis em relação ao uso de agrotóxicos nos alimentos não promove.

Quando o assunto recai nas políticas públicas que estão ligadas ao Estado, o que está em voga diz respeito aos determinantes da saúde. Tais determinantes significam categorias de fatores que condicionam a saúde das populações, tais como: (1) os determinantes ambientais, que levam em consideração as condições de habitação, água e esgoto, taxa de desemprego, áreas de lazer; (2) os determinantes sociais, que afetam aspectos individuais e biológicos, como idade, sexo e estilo de vida, mas que consideram também e, principalmente, aspectos como o grau de educação disponível, a inclusão social, as condições de vida, de uma maneira geral, envolvendo a cultura estabelecida; (3)os determinantes econômicos, que estão diretamente ligados ao desempenho econômico do país e, infringindo outros determinantes, como nas questões de emprego, de habitação etc. (CARRAPATO; CORREIA; GARCIA, 2017).

Tais questões, de aspectos macroestruturais, envolvem a situação geral em sociedade, portanto, reivindicam a funcionalidade, a partir de ações governamentais, da promoção da saúde. Inúmeros são os exemplos: acesso a transporte público de qualidade promove saúde; a 
criação de leis que multam quem dirige alcoolizado ou sem cinto de segurança inibe essas ações e, portanto, facilita a escolha saudável, promovendo saúde. Tais exemplos demonstram que promover saúde vai além de questões físicas e psicológicas, mas também, questões sociais, econômicas, ambientais e políticas, abrangendo a questão cultural. A humanidade ainda busca transformar o paradigma vigente para a saúde através da conciliação de paradoxos e desigualdades crescentes em âmbito social, econômico, político, cultural e ambiental, sendo necessária a implantação de uma nova cultura da saúde (MENDES, 2004).

Portanto, para se falar em um estilo de vida saudável, muito comumente pautado tanto por jornais como por especialistas em seus canais de comunicação, primeiramente é preciso compreender que esse conceito, em sua concretude, só se exerce a partir de um entendimento maior, o da promoção da saúde. Percebe-se que o termo "saudável" é utilizado no sentido de atribuir ao corpo mais saúde (SANTOS et. al, 2019), no entanto, é corriqueiramente utilizado de forma individualizante, concepção que vai de encontro aos preceitos da promoção da saúde.

Há uma complexidade nas relações entre vida saudável, saúde e meio social composto por vários elementos informativos que, separados, se constituem em perspectivas, em partes que não concluem o todo. Isso acontece na tentativa de simplificação do todo, na tentativa de dar conta de uma realidade, criando diferentes contextos nos quais o conceito vida saudável pode ser encaixado (ALMEIDA; CASOTTI; SENA, 2018). É preciso dialogar com os conceitos para que, de fato, uma educação em torno do que é saúde possa ser construída para a promoção da saúde de modo coletivo. Nesse sentido, os meios de comunicação exercem, através da mediação, papel importante na construção da significação de conceitos e perspectivas que, ao serem divulgadas, se disseminam entre a população como uma ideia do que é uma vida saudável.

Uma comunicação bem-feita pode causar o efeito de persuasão nas pessoas em relação a mudanças de hábitos, por exemplo. Além disso, pode causar impacto ao noticiar sobre o que não está funcionando socialmente, fazendo que as pessoas busquem reivindicar melhores condições de vida. A adoção de hábitos saudáveis pode partir de uma decisão pessoal, mas a promoção da saúde é determinante para que as pessoas tenham consciência da melhor conduta sobre sua saúde (RENAUD, 2010). Na próxima seção apresentaremos, em continuidade à discussão, como a midiatização atrelada às novas mediações fazem parte decisiva de um novo processo entre os atores sociais da saúde e as informações que circulam no meio social. 


\section{Midiatização e novas mediações}

Comumente generalizadas como "mídia", as práticas midiáticas que envolvem meios de comunicação de massa fazem parte do cenário cotidiano e possuem a capacidade de centralizar a comunicação e a informação cujo modelo horizontal consagrado está se encaminhando para uma mudança estrutural em relação à transmissão de informações. “Uma transformação mais profunda está em curso, uma transformação que desafia a ontologia na qual o paradigma da comunicação de massa foi baseado" (COULDRY, 2010, p. 53).

Análises sobre os meios de comunicação são fundamentais para a compreensão do contexto social, econômico e político de um estado-nação, uma vez que as instituições midiáticas atravessam sua organização e contribuem para sua sustentação (COULDRY, 2010), não podendo ser encarados como aparatos separados do meio social. A "mídia é, se nada mais, cotidiana, uma presença constante em nossa vida diária, enquanto ligamos e desligamos, indo de um espaço, de uma conexão midiática, para outro" (SILVERSTONE, 2002, p. 20).

Originalmente, a palavra comunicação abrange dois sentidos: o de partilhar algo e o de dar conhecimento, informar. A comunicação desponta dialógica, como um processo horizontal entre os indivíduos. As redes sociais, a partir de mecanismos como curtidas, retweets, compartilhamentos e com a possibilidade de comentários nas postagens, demonstram que a informação pode, através da comunicação entre indivíduos, ser complementada, ser dialógica, ser contínua em grande medida. As redes sociais demonstram a dinamicidade não só da comunicação, mas do processo informacional. É o que Braga (2012) esclarece como "fluxo adiante":

Esse "fluxo adiante" acontece em variadíssimas formas - desde a reposição do próprio produto para outros usuários (modificado ou não); à elaboração de comentários - que podem resultar em textos publicados ou em simples "conversa de bar" sobre um filme recém visto; a uma retomada de ideias para gerar outros produtos (em sintonia ou contraposição); a uma estimulação de debates, análises, polêmicas - em processo agonístico; a esforços de sistematização analítica ou estudos sobre o tipo de questão inicialmente exposta; passando ainda por outras e outras possibilidades, incluindo aí, naturalmente a circulação que se manifesta nas redes sociais. (BRAGA, 2012, p. 39-40). 
Torna-se nítido que a mudança tem como cerne a relativização do uso dos processos tecnológicos nas relações comunicacionais para além do campo da Comunicação que tem na formação de seus atores constituintes, profissionais das mídias. Isso, na prática social, transforma-se em um ecossistema que associa antigos e novos circuitos de interação, remodelando a ideia de mediação da informação e a ideia de hierarquização dos meios de comunicação na relação com os públicos.

0 processo de midiatização, à vista disso, contribui para um entendimento sobre tais transformações, sendo o conceito descrito a partir de Hjarvard (2012) cooperador da fundamentação sobre midiatização a partir de um quadro teórico que considera esse conceito importante para entender questões já antigas sobre a influência da mídia na cultura de um povo enquanto sociedade, já que a nomenclatura consegue angariar uma compreensão de "como a mídia se difunde para, se confunde com e influencia outros campos ou instituições sociais" (HJARVARD, 2012, p. 54). Segundo o autor, os processos midiáticos tornaram-se onipresentes na sociedade contemporânea, por isso, é preciso entender as mudanças que essa presença midiática causa nas funções e nas estruturas do ambiente social e cultural.

Aqui, midiatização é utilizada como conceito central em uma teoria sobre a importância intensificada e mutante da mídia dentro da cultura e da sociedade. Por midiatização da sociedade, entendemos o processo pelo qual a sociedade, em um grau cada vez maior, está submetida a ou torna-se dependente da mídia e de sua lógica. Esse processo é caracterizado por uma dualidade em que os meios de comunicação passaram a estar integrados às operações de outras instituições sociais ao mesmo tempo em que também adquiriram o status de instituições sociais em pleno direito. (HJARVARD, 2012, p. 64, grifos do autor).

Diante da explicação conceitual apresentada, vale ressaltar o papel da tecnologia no processo de midiatização, não apenas com enfoque tecnicista, mas entendendo sua dimensão social, a qual situa tecnologia e sociedade de maneira relacional tendo como ponto principal a comunicação midiática contemporânea ao ditar as formas de interação. 0 processo de midiatização, entretanto, não pode ser compreendido de modo esclarecedor sem uma relação integrada à mediação que, levando em consideração a perspectiva de Martín-Barbero (2009), corresponde a processos de negociação, que geram sentidos culturais, sociais, políticos e econômicos, os quais são praticados por atores sociais entre si, mas que também são estabelecidos amplamente a partir de artifícios midiáticos que, do mesmo modo, criam negociações de sentido. 
É importante destacar, ainda, que os meios de comunicação de massa participam de forma decisiva na transformação das instituições modernas. Por conseguinte, com o surgimento de outros meios de comunicação, como as redes sociais na internet, há uma potencialização que avança e acentua esse processo de midiatização vinculado à mediação, o qual faz que a interação entre as figuras emissor e receptor seja decisivamente remodelada (THOMPSON, 1998). As produções simbólicas das corporações midiáticas distribuídas através dos meios de comunicação é que mudaram e continuam modificando a comunicação na sociedade (HJARVARD, 2012).

À vista disso, a midiatização e a mediação não se anulam, imbricam-se no encadeamento comunicativo. A mediação concerne em um processo no qual a comunicação, através de um meio, pode influenciar tanto a mensagem quanto a relação entre emissor e receptor. No que diz respeito às fontes de notícias institucionais com apelo social renomado, a exemplo de profissionais da saúde, ao optarem pela utilização de redes sociais próprias em detrimento de jornais para se comunicar com a população, utilizam-se de uma forma e um conteúdo comunicacional distintos, e, tal escolha pode influenciar na relação entre esses profissionais e seus clientes. Entretanto, a escolha entre usar uma rede social ou um jornal não necessariamente altera o modo institucional como a saúde é enxergada socialmente. A mediação é a escolha pura de um meio específico que gere uma relação de comunicação.

[...] o termo mediação tem alcançado algumas dimensões predominantes: cognitiva (mediação discursiva entre sujeitos e realidade), interacional (prática social de construção de sentidos), institucional (atores com legitimidade social para ter uma atuação mediadora entre atores e campos sociais) e tecnológica (como dispositivo que viabiliza materialmente as interações). (FRANCISCATO, 2019, p. 7).

Já "a midiatização se refere a um processo mais a longo prazo, segundo o qual as instituições sociais e culturais e os modos de interação são alterados como consequência do crescimento da influência dos meios de comunicação" (HJARVARD, 2012, p. 66). Esses conceitos auxiliam no entendimento do processo no qual as fontes de notícias estão se especializando atualmente, principalmente através de assessorias de comunicação e das redes sociais. Isso altera drasticamente o modo como as instituições e pessoas renomadas se comunicam com a população e com os jornais a partir da esfera pública, transformando e ampliando modos de trabalho, o que interfere em aspectos principalmente econômicos e sociais. Hjarvard (2012) cristaliza essa compreensão por um ângulo institucional. Assim, "a 
sociedade contemporânea está permeada pela mídia de tal maneira que ela não pode mais ser considerada como algo separado das instituições culturais e sociais" (HJARVARD, 2012, p. 54), de modo que:

[...] uma parte significativa da influência que a mídia exerce decorre do fato de que ela se tornou uma parte integral do funcionamento de outras instituições, embora também tenha alcançado um grau de autodeterminação e autoridade que obriga essas instituições, em maior ou menor grau, a submeterem-se a sua lógica. (HJARVARD, 2012, p. 54).

O autor brasileiro Sodré (2002) também auxilia na reflexão sobre mídia ao explicar esse novo momento social que remodela as interações dos sujeitos no tempo-espaço a partir da virtualidade como um novo bios existencial, ou seja, recordando a classificação de Aristóteles, no clássico Ética a Nicômaco, sobre os gêneros de existência: bios theoretikos (vida contemplativa, do conhecimento), bios politikos (vida política) e bios sapolaustikos (vida prazerosa, vida do corpo). Sodré (2002) sugere que se integre a ideia de bios midiático como intrínseco à existência humana, uma vez que a mídia se tornou componente fundamental da vida contemporânea. Assim, a concepção de bios midiático se torna possível a partir de uma midiatização social, a qual gera esse amplo e complexo ecossistema permeado por circuitos.

Um profissional da saúde, ao utilizar suas mídias sociais, consegue ampliar seu território de interação com quem se interessa pelo seu trabalho, podendo inclusive efetivar consultas on-line. Devido a essa forte ascendência dos processos de midiatização-mediação, é necessário compreender sua presença como um fenômeno atualmente percebido como recorrente no campo comunicacional e ligado à vida social, negando a ideia de que o espaço virtual é dissonante do real, principalmente, nesse caso, devido ao interesse público que a informação desses especialistas gera, o que pode causar reação no âmbito social, por exemplo, de mudanças de hábitos em relação à saúde.

O fenômeno da midiatização amplia as reflexões sobre mídias de tal maneira que envolve todo e qualquer indivíduo na contemporaneidade que estabeleça relações a partir de interações midiáticas, as quais envolvem diferentes e diversas experiências e práticas humanas, como relações educacionais, médicas, sociais, políticas, econômicas, religiosas etc. (LOPES, 2017). Esse contexto faz com que os campos sociais, "microcosmos relativamente autônomos" (BOURDIEU, 2003, p. 22), historicamente estabelecidos e que desempenham funções sociais, sofram intercepções de circuitos e façam parte de um novo e amplo espaço, 
um grande ecossistema. Assim, relacionam-se com um ambiente externo à lógica de campos para que não sejam invisibilizados de alguma maneira.

O trabalho informativo pode contribuir para promover saúde, uma vez que a comunicação e a informação são essenciais para expandir a ideia de promoção entre os sujeitos e para que essa problemática faça parte da agenda social, tornando-se um tema importante de opinião pública. Assim, mudanças podem ocorrer na busca pela equidade e pela qualidade de vida em sociedade. Um assunto fazer parte da opinião pública de uma sociedade consiste em aspecto essencial para que determinado tema consiga se transformar na prática social. A opinião pública considera a pluralidade de opiniões, o debate coletivo, importando apenas a expressividade e a relevância pública do tema (CERVELLINI; FIGUEIREDO, 1996). É preciso, portanto, que a promoção da saúde se torne um tema pautado pela população e, assim, passe a incomodar o poder público, sendo o jornalismo e os especialistas em saúde contribuintes decisivos no que diz respeito a pautar e incomodar.

Anderson, Bell e Shirky (2013) propõem a adoção do termo "ecossistema jornalístico", o qual parte do pressuposto de que há uma interdependência mútua entre os principais atores envolvidos na produção e circulação de informações jornalísticas. "Hoje, é imperativo que a instituição tenha a capacidade de estabelecer parcerias (formais e informais) possibilitadas pelo novo ecossistema" (ANDERSON; BELL; SHIRKY, 2013, p. 76), o que demonstra a importância de se efetuar uma aproximação com outras organizações e nas redes sociais digitais.

A influência da mídia na ação de outros atores que não midiáticos demonstra a capacidade diferencial que atores de outros campos podem buscar se souberem trabalhar com mídias, tornando isso um tipo de capital dentro de um campo não-midiático, devido ao poder simbólico da mídia. Isto é, esse poder de construir a realidade social, a partir da seleção de categorias-chave e da penetração cognitiva e social que gera (BOURDIEU, 1990). Desse modo, estamos diante de uma nova tentativa de interação comunicacional entre os sujeitos, como explica Braga (2012):

Assim como, desde o século XVII, a imprensa se desenvolveu como um componente estruturante da sociedade (notadamente a europeia), na medida em que esta buscava organizar, diversificadamente, as potencialidades da escrita a serviço de seus interesses múltiplos e frequentemente contraditórios; assim também vemos os processos de internacionalidade midiatizante estimulando os modos pelos quais a sociedade se comunica e, em consequência, tentativamente se organiza. (BRAGA, 2012, p. 37). 
Ao abordarem temas de saúde que comportam uma vida saudável em sociedade, os atores que fazem parte do ecossistema jornalístico visibilizam o tema da promoção da saúde, seja demonstrando a inexistência dela, seja mostrando como tomar atitudes mais saudáveis na vida cotidiana. Em contrapartida, cada vez mais prescrições e recomendações ditas pelos jornais são desmentidas ou questionadas, o que cria insegurança nos cidadãos, por exemplo, quando o jornal enuncia uma posição contrária ou favorável em relação aos alimentos geneticamente modificados, sendo que ainda não há uma posição única sobre o assunto nem mesmo entre os cientistas e especialistas (OLIVEIRA, 2013).

As informações sobre saúde nas mídias sofrem a consequência de gerar uma dualidade social díspar: quando adequadamente divulgadas, podem auxiliar na conscientização popular, promovendo hábitos saudáveis, auxiliando na prevenção de doenças e instruindo em tratamentos. Uma comunicação equivocada, no entanto, pode ocasionar alarme sem necessidade na população e gerar errôneas expectativas em relação a descobertas sem validação da ciência (OLIVEIRA, 2014). 0 trabalho do jornalismo vai além do utilitário, tem de apreender saúde de maneira investigativa, alertando sobre o poder político na gestão da promoção da saúde, além de qualificar e empoderar as pessoas, por meio da informação, sobre o seu papel como comunidade em relação à saúde no seu bairro, na sua cidade e no seu país.

Os periódicos têm grande responsabilidade sobre o que informam e a respeito de a quem concedem voz. As fontes de notícias especializadas encontradas nos jornais precisam ser profissionais íntegros e compromissados com a ética e a investigação científica, que não mascarem informação para obter vantagens próprias ou para a empresa onde trabalham (BUENO, 2015). Os jornais precisam manter o acordo simbólico que há entre o jornalismo e a população, cujo compromisso jornalístico está alinhado com a verdade dos fatos e com os cidadãos que, por sua vez, legitimam o lugar de fala dos jornalistas ao privilegiarem os jornais como espaço de informação crível.

Profissionais da saúde, especialistas que possuem redes sociais e informam sobre saúde, podem também ser considerados credíveis e comprometidos com a informação adicionada em suas postagens públicas. Em um primeiro olhar, portanto, a informação postada por um dermatologista, por exemplo, em suas redes sociais, pode ser compreendida como de relevância e de credibilidade, assim como o é em um jornal, podendo atuar de forma próxima e complementar a informação jornalística. 
Para que a comunicação na informação em saúde seja efetivada em prol da população, Bueno (2007) exemplificou uma série de mudanças que precisam ocorrer de modo que haja uma ruptura do padrão atual de cobertura, o qual ainda privilegia um olhar autoritário sobre como ser saudável, além de trabalhar com uma interferência perniciosa dos interesses privados. É preciso aumentar o número de vozes do âmbito biomédico presentes nos jornais. Além disso, falta o diálogo analítico com profissionais de outras áreas que possam contribuir para o debate através de seus saberes, uma vez que pautar promoção da saúde exige tal interdisciplinaridade. Faz-se necessária uma autocrítica dos profissionais em seu trabalho jornalístico, pois, frequentemente, criam uma dependência e submissão nefasta no relacionamento com as fontes oficiais e com o poder político e econômico; informar sobre promoção à saúde tem de ter como pré-requisito a pauta sobre cultura, ou seja, mostrar que a saúde coletiva está intrinsicamente atrelada ao social, político, ambiental e econômico, desprivilegiando pautas de soluções milagrosas para a saúde. Finalmente, uma comunicação sobre o tema da promoção da saúde deve estar compromissada com a ética da informação, desconsiderando a fala de profissionais, indústrias e agências da saúde que tratam do tema de forma estritamente mercantilista (BUENO, 2007).

\section{Considerações finais}

Torna-se perceptível o campo de luta no qual a promoção da saúde está inserida. Promover saúde aparece como uma árdua tarefa, já que o contexto neoliberal, mercadológico e individualista atual salienta princípios opostos aos da coletividade, da equidade, da solidariedade e até mesmo da democracia. A conjuntura contemporânea é de risco, de redução de verbas, de precarização, de ameaças ao direito universal à saúde. Dessa forma, a militância se faz necessária como ferramenta de voz e visibilidade em prol do direito à saúde e, consequentemente, em prol da promoção da saúde das populações.

A Comunicação pode ser considerada central nessa questão entre o entendimento do público geral e a promoção da saúde, uma vez que, individualmente, a percepção e a conscientização para mudanças de hábitos e, coletivamente, a problematização e a visibilidade sobre a influência dos determinantes da saúde possuem mais chance de aceitação social por meio da persuasão. Para isso, é preciso uma comunicação em linguagem acessível e constante na vida cotidiana, fazendo do jornalismo uma importante ferramenta da comunicação para esse propósito. A promoção da saúde precisa ser tematizada pela imprensa 
através da inclusão, promovendo, como determinantes: educação, moradia, alimentação, renda, meio ambiente, justiça social e inclusive a paz.

\section{Referências}

ALMEIDA, C. B; CASOTTI, C. A; SENA, E. L. S. Reflexões sobre a complexidade de um estilo de vida saudável. Avances en Enfermería, [s. l.], v. 36, n. 2, p. 220-229, 2018.

AMPUJA, M. A sociedade em rede, o cosmopolitismo e o "sublime digital": reflexões sobre como a história tem sido esquecida na Teoria Social Contemporânea. Parágrafo, São Paulo, v. 3, n. 1, p. 55-68, 2015.

ANDERSON, C. W; BELL, E; SHIRKY, C. Jornalismo pós-industrial: adaptação aos novos tempos. Revista de Jornalismo ESPM, [s. l.], v. 5, n. 2, p. 30-89, abr/jun. 2013.

BOURDIEU, P. 0 poder simbólico. Lisboa: Difel, 1990.

BOURDIEU P. Os usos sociais da Ciência, por uma sociologia clínica do campo científico. São Paulo: Editora UNESP, 2003.

BRAGA, J. L. Circuitos versus Campos Sociais. In: MATTOS, M. A; JANOTTI JÚNIOR, J; JACKS, N (org.). Mediação e Midiatização. Salvador: EDUFBA/Compós, 2012, p. 31-52.

BUENO, W. C. Comunicação e promoção da saúde no Brasil. In: BAGRICHEVSKY M, ESTEVÃO A, PALMA A. A saúde em debate na educação física. Ilhéus: Editus; 2007, p. 231- 252.

BUENO, W. C. A comunicação da saúde na web: os compromissos de uma autêntica ação educativa. In: SANTOS, A. (org.). Caderno Mídia e Saúde Pública. Belo Horizonte: Escola de Saúde Pública/FUNED, 2006.

BUENO, W. C. Comunicação para a saúde: a prescrição deve ir além da competência técnica. In: PESSONI, A. (org.). Comunicação, Saúde e Pluralidade: novos olhares e abordagens em pauta. São Caetano do Sul: USCS, 2015, p. 65-85.

CARRAPATO, P; CORREIA, P; GRACIA, B. Determinante da saúde no Brasil: a procura da equidade na saúde. Saúde e Sociedade, São Paulo, v. 26, n. 3, p. 676-689, 2017.

CARTA DE OTTAWA. Carta de Ottawa: sobre promoção da saúde. Ottawa: OMS, 1986.

CERVELLINI, S; FIGUEIREDO, R. 0 que é opinião pública. São Paulo: Brasiliense, 1996.

COSTA; R. P; MISOCZKY, M. C; ABDALA, P. R. Z. Do dilema preventivista ao dilema promocionista: retomando a contribuição de Sérgio Arouca. Saúde Debate, [s. l.], v. 42, n. 119, p. 990-1001, 2018.

COULDRY, N. A mídia tem futuro? Matrizes, São Paulo, v. 4, n. 1, p. 51-64, 2010. 
DECLARAÇÃO DE ALMA-ATA. Declaração de Alma-Ata. Alma-Ata: OMS, 1978.

DEMARZO, M. M. P; AQUILANTE, A. G. Saúde escolar e escolas promotoras de saúde. In: Programa de Atualização em Medicina de Família e Comunidade. Porto Alegre: Artmed, 2008, p. 49-76.

FRANCA, V. R. V. L. Quéré: dos modelos da comunicação. Revista Fronteira, São Leopoldo, v. 5, n. 2, p. 37-51, 2003.

FRANCISCATO, C. E. Tecnologias digitais e temporalidades múltiplas no ecossistema jornalístico. Contracampo, Niterói, v. 38, n. 02, p. 132-146, 2019.

GADELHA, C. A; TEMPORÃO, J. G. Development, innovation and health: the theoretical and political perspective of the Health Economic-Industrial Complex. Ciência Saúde Coletiva, [s.l.], v. 23, n. 6, p. 1891-1902, 2018.

GOMES, W. Jornalismo e interesse público. In: GOMES, W. Jornalismo, fatos e interesses: ensaios de teoria do jornalismo. Florianópolis: Insular, 2009. p. 67-88.

HALL, S. A ideologia e a teoria da comunicação. Matrizes, São Paulo, v. 10, n. 3, p. 33-46, 2016.

HJARVARD, S. Midiatização: teorizando a mídia como agente de mudança social e cultural. Matrizes, São Paulo, v. 5, n. 2, p. 53-91, 2012.

HENRIQUES, R. P. Realismo, perspectivismo e a questão da objetividade jornalística. Princípios: Revista de Filosofia, [s. l.], v. 26, n. 50, p. 335-355, 2019.

LALONDE, M. A new perspective on the health of Canadians: a working document. Ottawa: Minister of Supply and Services Canada, 1981.

LERNER, K; SACRAMENTO, I. Saúde e Jornalismo: Interfaces Contemporâneas. Rio de Janeiro: Fiocruz, 2014.

LOPES, F; RUÃO, T; MARINHO, S; ARAÚJO, R. Jornalismo de saúde e fontes de informação: uma análise dos jornais portugueses entre 2008 e 2010, Derecho a Comunicar, [s. l.], v. 2, n.2, p. 100-120, 2011.

LOPES, F. L. Indagações à identidade jornalística na era do virtual e da cultura da rede. In: D’AVILA, C; TRIGUEIROS, U. Comunicação, Mídia e Saúde: novos agentes, novas agendas. Rio de Janeiro: Luminatti, 2017, p. 201-225.

MARTÍN-BARBERO, J. Dos meios às mediações: comunicação, cultura e hegemonia. Tradução: Ronald Polito e Sérgio Alcides. 6. ed. Rio de Janeiro: Editora UFRJ, 2009.

MENDES, I. A. C. Desenvolvimento e saúde: a declaração de Alma-Ata e movimentos posteriores. Revista Latino-americana Enfermagem, [s. l.], v. 12, n. 3, p. 447-458, 2004. 
MORAES, D. R; CASTIEL, L. D. O salutarismo de Robert Crawford e as atualizações do autoritarismo sanitário nosso de cada dia. Reciis - Revista Eletrônica de Comunicação, Informação \& Inovação em Saúde, Rio de Janeiro, v. 13, n. 1, p. 122-133, 2019.

OLIVEIRA, M. (Des) informação sobre saúde da mulher: investigar a imprensa é preciso. Revista Tempus - Actas de Saúde Coletiva. Brasília, v. 8, n. 4, p. 287-297, 2014.

OLIVEIRA, V. C. Os sentidos da saúde nas mídias jornalísticas impressas. Reciis - Revista Eletrônica de Comunicação, Informação \& Inovação em Saúde, Rio de Janeiro, v. 6. n. 4, 2013.

PAIM, J. S. O Que É O Sus. Rio de Janeiro: Fiocruz, 2009.

RENAUD, L. Les médias et la santé: de l'émergence à l'appropriation des normes sociales. Québec: Presses de l’Université du Québec, 2010.

ROCHA, R. M; PADILHA, M. A. Um debate possível: o saber fazer da promoção da saúde. Revista Brasileira de Pesquisa em Saúde, [s. l.], v. 18, n. 4, p. 4-6, 2016.

SANTOS, A. M; et. al. Corpo, saúde e sociedade de consumo: a construção social do corpo saudável. Saúde e Sociedade, São Paulo, v. 28, n. 3, p. 239-252, 2019.

SILVERSTONE, R. Por que estudar a mídia? São Paulo: Loyola, 2002.

SODRÉ, M. Antropológica do espelho: uma teoria da comunicação linear e em rede. 2. ed. Petrópolis: Vozes, 2002.

THOMPSON, J. B. A mídia e a modernidade: uma teoria social da mídia. Tradução: Wagner de Oliveira Brandão. Petrópolis: Vozes, 1998.

THOMPSON, J. B. A interação mediada na era digital. Matrizes, São Paulo, v. 12, n. 3, p. 17-44, 2018.

The mediatization of health: the prospects of a healthy life in the journalistic ecosystem

\begin{abstract}
This work presents a brief overview of the relationship between the media and health issues based on the role of specialized information sources, their particularities and discussions, in addition to the attempt to understand the role of information in the construction of health concepts in the current context of social media coverage. Thus, this article aims to bring together strands of study on the topic of mediatization of health and problematize the logic of the practice of building perspectives on healthy life, based on information sources in the journalistic ecosystem. The results showed that the new mediations create
\end{abstract}


complex relationships and interactions between the use of concepts in new social media by health professionals in their dynamics with the general public.

\section{Keywords}

Information sources; Health promotion; Health journalism; Communication and health; Mediatization

\section{Autoria para correspondência}

Thalita Mascarelo da Silva

thalitamascarelo@outlook.com

\section{Como citar}

SILVA, Thalita Mascarelo da; GENTILLI, Victor Israel. Midiatização da saúde: as perspectivas de uma vida saudável no ecossistema jornalístico. Intexto, Porto Alegre, n. 52, e-100236, jan./dez. 2021. DOI: http://dx.doi.org/10.19132/1807-8583202152.100236

Recebido em 04/02/2020

Aceito em 03/08/2021

(c) $(1)(9)$ 